http://jmscr.igmpublication.org/home/

ISSN (e)-2347-176x ISSN (p) 2455-0450

crossref DOI: https://dx.doi.org/10.18535/jmscr/v7i7.114

Journal Of Medical Science And Clinical Research

IGM Publication

An Official Publication of IGM Publication

\title{
Chronic Daily Headache \& its subtypes distribution according to age \& sex
}

\author{
Authors \\ Dr C.M. Agarwal ${ }^{1}$, Dr Pratik Jain ${ }^{2 *}$, Dr Gourav Goyal ${ }^{3}$ \\ ${ }^{1}$ Associate Professor, General Medicine, Mahatma Gandhi Medical College, Jaipur \\ ${ }^{2}$ Junior Resident, General Medicine, Mahatma Gandhi Medical College, Jaipur \\ ${ }^{3}$ Assistant Professor, Neurology, Mahatma Gandhi Medical College, Jaipur \\ *Corresponding Author \\ Dr Pratik Jain \\ Junior Resident, General Medicine, Mahatma Gandhi Medical College, Jaipur, India
}

\begin{abstract}
Background: Chronic daily headache is not a specific headache type, but a syndrome that includes various primary and secondary headaches. It affects approximately 3-5\% of the population. Females are affected 2 to 3 times more often than man. The present study is of Chronic Daily Headache \& it's subtypes distribution according to age \& sex.
\end{abstract}

Material \& Methods: This cross sectional study was done in Out Patient Department (OPD) of Mahatma Gandhi Hospital attached to Mahatma Gandhi Medical University, Jaipur located in North India providing secondary/tertiary medical care. Consecutive patients with chronic daily headache (CDH) attending the neurology and medicine Out Patient Department between September 2016 to September 2017 were enrolled for the study.

Results: The present study showed that the maximum number of the patients (65\%) were seen in the age group of 21-40 years and mean age of CDH patients was 34.21 \pm 11.82 years. It is seen that out of 200 patients, 120(60\%) patients had Chronic Migraine (CM), 80 (40\%) patients had Chronic Tension Type Headache (CTTH), 78 patients had Medication Overuse Headache and no one had Hemicrania Continua or New Daily Persistent Headache. Mean age of CM patients was lower (32.23 \pm 11.49$)$ as compared to mean age of CTTH patients (37.16 \pm 11.76$)$, this difference was statistically significant $(P=0.0036 * *)$. Sex wise distribution of the cases, female was 153 (76.5\%) and 47 (23.5) were males.

Conclusion: Chronic daily headache frequency \& its sub type CM \& CTTH are higher in females as compared to males. In females, CM is more common than CTTH \& in males, CTTH is more common than CM. CTTH affects at a higher age as compared to CM. Female to male ratio is higher in CM (5.3:1) as compared to CTTH (1.9:1).

Keywords: Chronic Daily Headache, Chronic Migraine, Chronic Tension Type Headache, New Daily Persistent Headache.

\section{Introduction}

Chronic daily headache is not a specific headache type but Chronic daily headache $(\mathrm{CDH})$ is a broad term which includes groups of headache disorders and it is not a diagnosis. "The term chronic daily headache is applied when the headache frequency is $\geq 15$ days a month for $\geq 3$ months". ${ }^{(1)}$ 
Chronic daily headache includes various primary and secondary headaches. Here chronic means either frequency of headache or duration of headache depending on specific headache type.

In several studies, they found difficulty in classifying frequent primary headaches using IHS criteria. Due to this fact Silberstein SD et al proposed new classification criteria for chronic daily headache in $1996 .{ }^{(1)}$ Under the general term of chronic daily headache, "Silberstein classified these daily or near daily headaches mainly into transformed migraine (TM), new daily persistent headache, chronic tension type headache, and hemicrania continua". Later on Chronic migraine replaced the term transformed migraine. Chronic daily headache mostly transforms from episodic headache through a gradual progression over months to years. It affects approximately $3-5 \%$ of the population. ${ }^{(2-4)}$ Females are affected 2 to 3 times more often than man.

Chronic migraine is one of the most common headache syndromes encountered at the major tertiary care centers. A precipitating factor is associated most of the time. It is also many times associated with medical conditions. It is also precipitated by physical or environmental factors like bright light/ visual stimuli, hypersensitivity reactions like allergy, urticaria, and drug hypersensitivity, risk factors like obesity, medication overuse, snoring, fasting, sleep deprivation, smoking, menstruation, odors, weather changes, dietary factors, psychiatric comorbidity \& stress. ${ }^{(5)}$ The present study is of chronic daily Headache \& it's subtypes distribution according to age $\&$ sex.

\section{Material \& Methods}

This cross sectional study was done in outpatient department (OPD) of Mahatma Gandhi Hospital attached to Mahatma Gandhi Medical University, Jaipur located in North India providing secondary/tertiary medical care. The study was approved by the Institutional Ethics Committee.

\section{Patient's sample}

Consecutive patients with chronic daily headache $(\mathrm{CDH})$ attending the neurology and medicine Out Patient Department between September 2016 to September 2017 were enrolled for the study. The inclusion and exclusion criteria for the subjects in the study groups as given below.

\section{Inclusion Criteria}

1. Age $\geq 18$ years and $\leq 65$ years

\section{Exclusion Criteria}

1. Age $<18$ years

2. Patients who have intracranial space occupying lesion

3. Patients with a concomitant medical illness such as end-stage organ failures e.g. renal, cardiac, hepatic, respiratory, secondary causes of $\mathrm{CDH}$

\section{Diagnosis of chronic daily headache and its subtypes}

We are doing the epidemiological study so it is necessary to know the definition of diagnosis to define who is suffering from disease and who is not. Chronic daily headache includes various primary and secondary headaches and it is characterized by very frequent headache each around for $\geq 4$ hours ( $\geq 15$ days a month for atleast 3 months)

The classification of $\mathrm{CDH}$ as a form of headache is based upon criteria given by Silberstein and Lipton (the SL criteria) ${ }^{(\mathbf{1})}$ and according to prevalence we include only 5 frequent subtypes of frequent headache and we consider definition according to ICHD-3 beta classification criteria. As we are studying only 5 frequent subtypes.

- Chronic migraine headache

- Chronic tension-type headache

- Medication overuse headache

- Hemicrania Continua

- New daily persistent headache

So here chronic daily headache is characterized by very frequent headache each around for 4 hours ( $\geq 15$ days a month) including headache associated with medication overuse. And we will define each 


\section{JMSCR Vol||07||Issue||07||Page 644-648||July}

headache types according to diagnostic criteria of ICHD-3 beta classification.

So to identify the type of headache we asked about duration of headache, duration of each headache attack, frequency of headache per month, associated symptoms, functional disability, analgesic use and response to treatment.

\section{Results}

The present study showed that the maximum number of the patients $(65 \%)$ were seen in the age group of 21-40 years and mean age of $\mathrm{CDH}$ patients was $34.21 \pm 11.82$ years (table 1 ).

Table 1: Chronic Daily Headache (CDH) distribution according to Age

\begin{tabular}{|c|c|c|}
\hline Age Group (Years) & CDH & Percentage \\
\hline $18-20$ & 20 & $10 \%$ \\
\hline $21-30$ & 78 & $39 \%$ \\
\hline $31-40$ & 52 & $26 \%$ \\
\hline $41-50$ & 26 & $13 \%$ \\
\hline $51-60$ & 24 & $12 \%$ \\
\hline $61-65$ & 0 & $0 \%$ \\
\hline Mean age \pm SD & \multicolumn{2}{|c|}{$34.21 \pm 11.82$} \\
\hline
\end{tabular}

Chronic Daily Headache is more common in female as compared to male. In both male and female highest number of patients were found in the same age group of 21-30 years. Mean age of male was $35.23 \pm 13.89$ years \& in females was $33.89 \pm 11.14$ years, but statistically not significant $(\mathrm{p}$-value $=0.4963)($ Table 2$)$.

Table 2: Chronic Daily Headache (CDH) distribution according to age and sex

\begin{tabular}{|c|c|c|c|}
\hline Age Group & Male & Female & Total \\
\hline$<21$ & 3 & 17 & 20 \\
\hline $21-30$ & 23 & 55 & 78 \\
\hline $31-40$ & 5 & 47 & 52 \\
\hline $41-50$ & 8 & 18 & 26 \\
\hline $51-60$ & 8 & 16 & 24 \\
\hline$>60$ & 0 & 0 & 0 \\
\hline TOTAL & 47 & 153 & 200 \\
\hline Mean age \pm SD & $35.23 \pm 13.89$ & $33.89 \pm 11.14$ & $\mathrm{P}=0.4963$ \\
\hline
\end{tabular}

It is seen that out of 200 patients, $120(60 \%)$ patients had Chronic Migraine (CM), 80 (40\%) patients had Chronic Tension Type Headache (CTTH), 78 patients had Medication Overuse Headache and no one had Hemicrania Continua or New Daily Persistent Headache. All 78 patients with Medication overuse Headache had either
Chronic Migraine or Chronic Tension Type Headache (table 3).

Table 3: Chronic Daily Headache according to its subtypes

\begin{tabular}{|l|c|}
\hline Subtypes & Numbers \\
\hline Chronic Migraine & 120 \\
\hline Chronic Tension Type Headache (CTTH) & 80 \\
\hline New Daily Persistent Headache & 0 \\
\hline Medication Overuse Headache & 78 \\
\hline Hemicrania Continua & 0 \\
\hline
\end{tabular}

Mean age of $\mathrm{CM}$ patients was lower $(32.23 \pm 11.49)$ as compared to mean age of CTTH patients $(37.16 \pm 11.76)$, this difference was statistically significant $\left(\mathrm{P}=0.0036^{* *}\right)$ (table 4$)$.

Table 4: Chronic Migraine (CM) and Chronic Tension Type Headache (CTTH) distribution according to age

\begin{tabular}{|c|c|c|c|}
\hline Age Group (Yrs) & CM & CTTH & Total \\
\hline$<21$ & 17 & 3 & 20 \\
\hline $21-30$ & 44 & 34 & 78 \\
\hline $31-40$ & 34 & 18 & 52 \\
\hline $41-50$ & 12 & 14 & 26 \\
\hline $51-60$ & 13 & 11 & 24 \\
\hline$>60$ & 0 & 0 & 0 \\
\hline TOTAL & $120(60 \%)$ & $80(40 \%)$ & 200 \\
\hline Mean age \pm SD & $32.23 \pm 11.49$ & $37.16 \pm 11.76$ & $\mathrm{P}=0.0036^{* *}$ \\
\hline
\end{tabular}

In our study showed that the among female CM was more common than CTTH (F:M was 5.3:1) and among male CTTH was more common than $\mathrm{CM}$ (F:M was 1.9:1) (table 5).

Table 5: Chronic Migraine (CM) and Chronic Tension Type Headache (CTTH) distribution according to sex

\begin{tabular}{|c|c|c|c|}
\hline Gender & CDH & CM & CTTH \\
\hline Female & 153 & 101 & 52 \\
\hline Male & 47 & 19 & 28 \\
\hline Female: Male & $\mathbf{3 . 2 5 : 1}$ & $\mathbf{5 . 3 : 1}$ & $\mathbf{1 . 9 : 1}$ \\
\hline
\end{tabular}

\section{Discussion}

In this study, 200 patients of $\mathrm{CDH} \geq 18$ years to $\leq 65$ year age group were studied. The maximum number of cases were found in 21-30 and 31-40 year age group $78(39 \%)$ and $52(26 \%)$ cases respectively. No cases were found in 61-65 year age group ( $0 \%$ cases). The mean age of patients who fulfilled $\mathrm{CDH}$ criteria was $34.21 \pm 11.82$ years. Sex wise distribution of the cases, female was $153(76.5 \%)$ and 47 (23.5) were males. Ratio 
being was 3.3:1 female: male. The mean age of female CDH subjects $(33.89 \pm 11.14)$ was lower than male $\mathrm{CDH}$ subjects $(35.23 \pm 13.89)$, but it was statistically insignificant ( $\mathrm{P}$-value $=0.4963)$. In this study mean age was lower compared to western studies may be because of the ignorant behavior of older people towards headache in India.

Castillo J et al in 1998 found the highest number of cases in 41 to 55 years age group and lowest in 65 year age group and female to male ratio was 8.7:1. ${ }^{(6)}$ In another study conducted by Lu SR et al in $2001^{3}$ on 108 patients of $\mathrm{CDH}$, the mean age was $39 \pm 15$ years (range 15-78 years). Mean age of $\mathrm{CM}$ was $37 \pm 14$ years. Mean age of CTTH was $42 \pm 15$ years and female to male ratio was 2.6:1.

Queiroz LP et al (2008) found that the highest number of cases in 30-39 year age group and female to male ratio was $2.4: 1 .^{(7)}$

In the current study chronic daily headache subtypes were studied. Chronic migraine was the most common $\mathrm{CDH}$ subtype $(\mathrm{n}=120)$ which was seen in $60 \%$ of all $\mathrm{CDH}$ subjects. 80 subjects met the CTTH criteria, which were $40 \%$ of all CDH subjects. 78 subjects also fulfilled $\mathrm{MOH}$ criteria, out of which 58 were $\mathrm{CM}$ subjects and 20 were CTTH subjects. 78 subjects had $\mathrm{MOH}$ either associated with $\mathrm{CM}$ or CTTH. No subject of another type of $\mathrm{CDH}$ were found in this study. The mean age of patients with $\mathrm{CM}$ was $(32.23 \pm 11.49$ years) and with CTTH was (37.16 \pm 11.76 years), P-value $<0.0036$. The mean age of $\mathrm{CM}$ was significantly lower than that of CTTH. This suggests CTTH affects at higher age compared to CM. Similar results were found in western studies. ${ }^{3,6}$ Out of 153 female $\mathrm{CDH}$ subjects, 101 had CM \& 52 had CTTH. Out of 47 male CDH subjects, 28 had CTTH \& 19 had CM. So higher female to male ratio was noted in $\mathrm{CM}$ (5.3:1) as compared to that of CTTH (1.9:1). This also suggests $\mathrm{CM}$ is more common in Females compared to CTTH \& in males CTTH is more common than CM.

In the study conducted by Pascual et $\mathrm{al}^{8}$ in 2001 on 89 subjects of CDH 42 had CTTH, 45 had CM \& 2 had NDPH. Mean age of CM was $47 \pm 14$ years \& CTTH $52 \pm 18$ years, p value 0.035 , \& out of 42 subjects of CTTH 38 (90.55\%) were female $\& 4$ were male $(9.45 \%)$. Out of 45 subjects of CTTH $40(88.9 \%)$ were female. ${ }^{(8)}$

In another study conducted by Juang et al on 108 patients. Out of $108 \mathrm{CDH}$ subjects 59 had CM, 47 had CTTH \& 2 subjects classified as "other CDH". Mean age of CM was $37 \pm 14$ years \& CTTH $42 \pm 15$ years. out of 59 subjects of CM , 50 were female \& 9 were male. Out of 47 subjects of CTTH, 28 were female \& 19 were male. ${ }^{(9)}$

\section{Conclusion}

Chronic daily headache frequency \& its subtype CM \& CTTH are higher in females as compared to males. In females, $\mathrm{CM}$ is more common than CTTH \& in males, CTTH is more common than CM. CTTH affects at a higher age as compared to $\mathrm{CM}$. Female to male ratio is higher in CM (5.3:1) as compared to CTTH (1.9:1).

\section{References}

1. Silberstein SD, Lipton RB, Sliwinski M. Classification of daily and near daily headaches: field trial of revised IHS criteria. Neurology 1996; 47:871.

2. Scher AI, Stewart WF, Liberman J, Lipton RB. Prevalence of frequent headache in a population sample. Headache 1998; 38:497.

3. Lu SR, Fuh JL, Chen WT, et al. Chronic daily headache in Taipei, Taiwan: prevalence, follow-up and outcome predictors. Cephalalgia 2001; 21:980.

4. Wang SJ, Fuh JL, Lu SR, et al. Chronic daily headache in Chinese elderly: prevalence, risk factors, and biannual follow-up. Neurology 2000; 54:314.

5. Pryse-Phillips WE, Dodick DW, Edmeads $\mathrm{JG}$, et al. Guidelines for the diagnosis and management of migraine in clinical practice. Canadian Headache Society. CMAJ. 1997;156:1273-1287.

6. Castillo J, Munoz P, Guitera V, Pascual J. Epidemiology of chronic daily headache in 
the general population. Headache 1999; 39:190-6.

7. Queiroz LP, Peres MFP, Kowacs F, et al. Chronic daily headache in Brazil: A nationwide population-based study. Cephalalgia 2008;28:1264-1269.

8. Julio Pascual, Rafael Colás, Jesús Castillo. Epidemiology of chronic daily headache. Current Pain and Headache Reports, December 2001, Volume 5, Issue 6, pp 529-536.

9. Juang KD, Wang SJ, Fuh JL, Lu SR, Su TP. Co-morbidity of depressive and anxiety disorders in chronic daily headache and its subtypes. Headache. 2000;40:818-23. 